\title{
Assessment of the potential contamination risk of nitrate in groundwater using indicator kriging (in Amol-Babol Plain, Iran)
}

\begin{abstract}
In arid and semi-arid regions such as Amolï Babol Plain in north Iran, groundwater is a major source of drinking water. Excessive usage of fertilizers in agricultural land, domestic sewage and industrial wastewater may result in nitrate contamination. The main objective of this study is to assess the potential contamination risk of nitrate pollution. The groundwater samples were collected from 100 agriculture wells during wet and dry seasons in 2009 and analyzed for nitrate concentration. Indicator kriging (IK) method is applied to create maps indicating the predicted probability of nitrate concentrations in groundwater exceeding the WHO drinking water standard of $10 \mathrm{mg} / \mathrm{L}-\mathrm{N}$. Based on the risk probability maps, some areas on the southern side of Babol City and the north and north-western side of Amol City showed a high probability of nitrate contamination. Seasonal maps indicated that the probability of nitrate contamination increased in the wet season, compared to the dry season in the study area, due to increase runoff from irrigated lands. Indicator kriging with local indicator thresholds is shown to be a reliable method to assess uncertainty in the estimation.
\end{abstract}

Keyword: Nitrate; Indicator kriging; Groundwater; Uncertainty; Amolï Babol; Iran 